\title{
POST-TEST SIMULATIONS FOR THE NACIE-UP BENCHMARK BY STH CODES
}

\author{
N. Forgione*, D. Martelli§, G. Barone\$, F. Giannetti ${ }^{\circ}$, P. Lorusso $^{\circ}$, T. Hollands`, A. Papukchiev^, \\ M. Polidori\#, A. Cervone\#, I. Di Piazza $\S$ \\ * DICI - Università di Pisa, L.go Lucio Lazzarino n. 2, 56122 Pisa, Italy \\ $\S$ ENEA, C.R. Brasimone, 40032 Camugnano (BO), Italy \\ \$ ENEA, C.R. Frascati, 00044 Frascati (RM), Italy \\ ○DIAEE - Nuclear Section, "Sapienza” Università di Roma, 00186 Roma, Italy \\ ^ GRS, Cooling Circuit Department Reactor Safety Research Division, Garching, Germany \\ \# ENEA, C.R. Bologna, Via Martiri di Monte Sole n. 4, 40129 Bologna, Italy \\ Corresponding author E-mail: nicola.forgione@unipi.it
}

\begin{abstract}
This paper illustrates the results obtained in the last phase of the NACIE-UP benchmark activity foreseen inside the EU SESAME Project. The purpose of this research activity, performed by system thermal-hydraulic (STH) codes, is finalized to the improvement, development and validation of existing STH codes for Heavy Liquid Metal (HLM) systems. All the participants improved their modelling of the NACIE-UP facility, respect to the initial blind simulation phase, adopting the actual experimental boundary conditions and reducing as much as possible sources of uncertainty in their numerical model. Four different STH codes were employed by the participants to the benchmark to model the NACIE-UP facility, namely: CATHARE for ENEA, ATHLET for GRS, RELAP5-3DC for the "Sapienza" University of Rome and RELAP5/Mod3.3(modified) for the University of Pisa. Three reference tests foreseen in the NACIE-UP benchmark and carried out at ENEA Brasimone Research Centre were analysed from four participants. The data from the post-test analyses, performed independently by the participant using different STH codes, were compared together and with the available experimental results and critically discussed.
\end{abstract}

Keywords: Experimental data, NACIE-UP facility, STH codes, Benchmark, HLM reactors

\section{INTRODUCTION}

The European HORIZON2020 project SESAME coordinates series of thermal hydraulics simulations and experiments for the safety assessment of metal cooled nuclear reactors, in order to support the development of the European Liquid Metal Fast Reactors (LMFRs) - ASTRID, MYRRHA, ALFRED, and SEALER (SESAME Handbook, 2019). A specific activity has been assigned to the benchmarking of STH alone and coupled CFD-STH codes, in support of improvement, development and validation of existing thermal hydraulic codes for Heavy Liquid Metal (HLM) coolants.

In particular, the selected blind benchmark exercise, proposed by the University of Pisa in collaboration with ENEA, was based on the experimental campaign performed by the NACIE-UP facility (I. Di Piazza et al., 2016). It is a $7.7 \mathrm{~m} \mathrm{high,} \mathrm{LBE} \mathrm{loop} \mathrm{that}$ investigates heat removal by natural convection from a fuel subassembly representative of a lead-cooled fast reactor (LFR) core. The experimental campaign focused on two preliminary tests and three fundamental tests. The two preliminary tests (Pre-Test-1 and Pre-Test-2) were used in the blind benchmark phase to characterize the system's heat losses and the relationship between the injected gas flow rate in the riser and the corresponding LBE mass flow in the primary loop. The three fundamental tests (Test-1, Test-2 and Test-3), taken as reference for the benchmark exercise, reproduced three different transients corresponding to, respectively, a gas lift reduction, a Fuel Pin Simulator (FPS) power reduction and a Protected Loss of Flow Accident (PLOFA) scenario.

The four participants executed both pre-test and post-test simulations of the reference tests, using the following STH codes:

- $\quad$ CATHARE (G. Geffraye et al., 2009) for ENEA;

- $\quad$ ATHLET (ATHLET User's Manual, 2016) for GRS;

- RELAP5-3D (RELAP5-3D Code Manual, 2013) for the University of Roma "Sapienza";

- RELAP5/Mod3.3(modified) (M. Angelucci et al., 2017) for the University of Pisa.

The present paper resumes the "post-test" activity, performed by the aforesaid four participants, to the benchmark activity on NACIE-UP experiments. In particular, the main factors at the origin of the discrepancies between blind simulations (N. Forgione et al., 2018) and experimental outcomes (ref. ENEA) were identified by each partner. The required improvements were implemented by the participants in order to generate an upgraded version of the NACIE-UP numerical model. Subsequently, these models were employed to carry out the "post-test" simulations and the simulated physical parameters were compared against the experimental data and the results were critically discussed. 


\section{THE NACIE-UP FACILITY}

NACIE-UP (I. Di Piazza et al., 2016) is an LBE loop facility, designed at ENEA Brasimone Research Centre, to qualify and characterize components, systems and procedures relevant for HLM nuclear technologies (see Figure 1). It is possible to carry out natural circulation and mixed convection experimental tests in the field of thermal hydraulics, fluid dynamics, chemistry control, corrosion and liquid metal heat exchange allowing the investigation of essential correlations for the design and development of new generation nuclear facilities. NACIE-UP is a rectangular loop (7.7 m height) consisting of two vertical pipes (O.D. 2.5”, S40), namely the downcomer and the riser, connected with two horizontal pipes (O.D. 2.5", S40). In the lower part of the riser a prototypical wire-spaced fuel pin bundle simulator (FPS) is installed, whereas a heat exchanger (HX) is placed in the upper part of the downcomer.

The difference in height, $\mathrm{H}$, between the centre of the FPS and the centre of the HX is about $5.5 \mathrm{~m}$ ensuring the driving force to sustain natural circulation inside the loop. NACIE-UP loop is entirely made of austenitic stainless steel, AISI 304, and can operate with both lead-bismuth (LBE) and lead as working fluid. The experimental tests, analysed here, were carried out using LBE. An argon gas injection device is placed inside the riser to promote the circulation inside the loop. An expansion vessel is installed, coaxially with the riser (on the top part), enabling the thermal expansion of the LBE during operational transient and allowing the separation of the argon from the LBE.

The heat exchanger is shell and tube type and was designed to exchange heat up to $250 \mathrm{~kW}$. It consists of 7 tubes arranged in a hexagonal lattice (one central and six surrounding tubes). The tubes are double-wall type to mitigate the axial thermal stresses, caused by the differential thermal expansion, and to avoid accidental contact of the liquid metal with water. The gap between the two walls is filled by steel powder to guarantee the thermal flux towards secondary water. The HX is composed of two separated shell sections: a cross-flow low power section ( $0-30 \mathrm{~kW})$ and a counter-current high-power section $(30-250 \mathrm{~kW})$, both connected to the pressurized water secondary side. The secondary side is a 16 bar pressurized water loop with a circulation pump, a pre-heater, the HX shell side, an air-cooler and a pressurizer.

The FPS consists of 19 wire-spaced electrical pins, arranged in a triangular lattice by a suitable hexagonal wrapper. The pin has a diameter $\mathrm{D}=6.55 \mathrm{~mm}$ and the pitch-to-diameter ratio $(\mathrm{P} / \mathrm{D})$ is 1.28 . The maximum power of the bundle is about $235 \mathrm{~kW}$, corresponding to a maximum wall heat flux close to $1 \mathrm{MW} / \mathrm{m} 2$. The overall layout of the FPS with its main dimensions is depicted in

Figure 2. On the pin foot, a bottom grid is positioned to keep the bundle in place.

The total length, which includes the non-active length and the electrical connectors, is $2000 \mathrm{~mm}$, while the active part is $600 \mathrm{~mm}$ long.
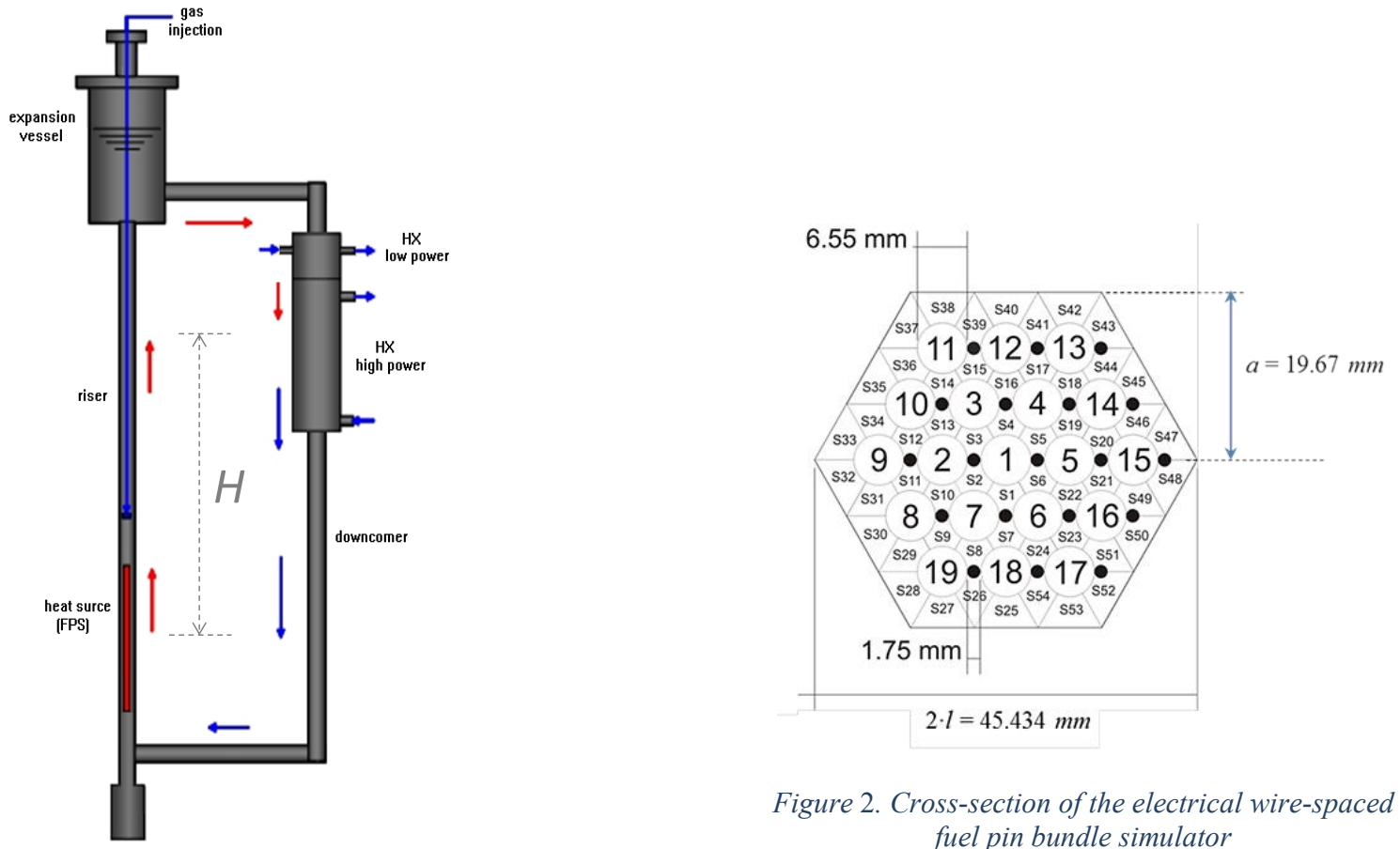

Figure 2. Cross-section of the electrical wire-spaced fuel pin bundle simulator

Figure 1. Schematic representation of the NACIE-UP primary loop

\section{NUMERICAL MODEL UPGRADE}

In the second phase of the NACIE-UP benchmark, the experimental data are made available to the participants in order to allow them to improve their models based on experimental feedback. The comparison of the experimental data with the outcomes from the blind simulations has highlighted the numerical model features requiring adjustments for the post-test analysis. Generally, for all 
three tests two major discrepancies with respect to the experimental data were identified by all the participants (N. Forgione et al., 2018) and consist of:

- $\quad$ higher values of the simulated LBE mass flow rate circulating in the loop, in both gas-enhanced and natural circulation that has required a re-assessment of the loop pressure drops;

- $\quad$ lower simulated loop mean temperature ascribable to the HX numerical model.

In the following are considered in detail the changes made by UniPi to their numerical model, taking into account that all participants performed similar upgrades to their models.

\subsection{Loop pressure drops}

The main contribution to the entire loop pressure drops is associated with the wire spaced bundle constituting the FPS. Therefore, a proper modelling of this component is essential for the prediction of the circulating flow and, consequently, the loop temperature field. As an example, for UniPi the comparison between the "blind" simulation and experimental results, showed, for all tests, an overestimation ( 25 to $45 \%$ ) of the mass flow rate of LBE circulating in the loop, indicating that there was a substantial underestimation of the pressure drops in the FPS. Figure 3 illustrates the flow rate comparison for Test3, in which both gas assisted and natural circulation occur.

The main reason of the "blind" model FPS pressure drop underestimation is related to the fact that the loop pressure drops were assessed in accordance with the experimental outcomes from a preliminary test (Pre-Test2) executed for this specific purpose. The test was carried out in isothermal conditions to assess solely the driving force deriving from the drag action of the injected gas, without accounting for the contribution of the thermal buoyancy. A curve defining the relationship between the injected gas flow and the LBE mass flow rate in the loop was derived and the experimental relationship was subsequently used to calibrate the pressure loss coefficients in the RELAP5 "blind model".

Figure 4 illustrates the experimental outcomes from the Fundamental Tests compared with the experimental data obtained from the Pre-Test 2 (N. Forgione et al., 2018), used for the "blind model" calibration. As can be inferred, the two experimental trends exhibit a clear inconsistency among them. Namely, the outcomes for the Fundamental Tests, at different level of FPS power (50 and $100 \mathrm{~kW}$ ), are characterized by lower mass flow rate for equal values of gas flow, despite the additional contribution of the thermal buoyancy. Therefore, the calibration procedure performed using the Pre-Test 2 (isothermal test) was not considered reliable and it was suggested to refer to the Fundamental Tests to correctly recalibrate the pressure losses for the "post-test" simulations.

The recalibration of the "post-test" model pressure drops has been performed by all benchmark participants, considering that the main contribution to the pressure drop in the NACIE-UP loop comes from the $1.3 \mathrm{~m}$ long wire spaced pin bundle that constitute the FPS. Therefore, the choice of a convenient methodology to simulate the friction losses in that zone was mandatory for the improved outcomes of the simulations.

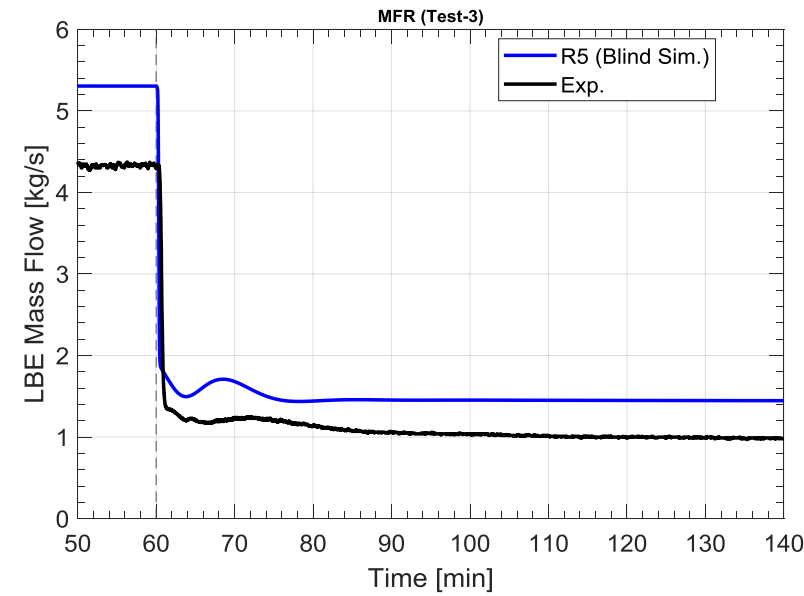

Figure 3. LBE mass flow rate (Test-3)

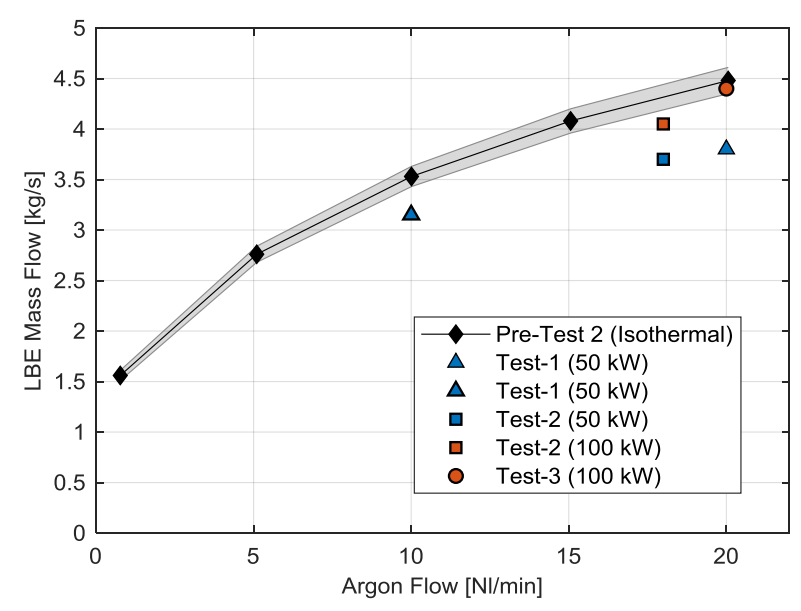

Figure 4. Experimental data of LBE mass flow vs. argon flow

Among the existing correlations (S.K. Chen et al., 2014) for the prediction of pressure drops in wire-spaced hexagonal array pin bundles, the simplified Cheng-Todreas correlation (S.K. Cheng and N.E. Todreas, 1986) was identified as the most appropriate for the NACIE-UP configuration. The Rehme correlation (K. Rehme, 1973) was assessed as well, yet, providing an underestimation of the pressure losses.

The Darcy friction factor as a function of the FPS Reynolds number is reported in Figure 5, for the two above-mentioned correlations, together with the results from a CFD assessment on NACIE-UP bundle (R. Marinari, 2014). These latter are in good agreement with Cheng-Todreas correlation for Reynold numbers higher than 5000 (forced circulation regime) while for lower Reynolds numbers (natural circulation regime) they overestimate Cheng-Todreas.

The implementation of the Cheng-Todreas correlation in the numerical model was made through the Junction Form Loss Data cards, where the form loss $\mathrm{K}$, set for forward and reverse flow direction, is calculated from:

$$
\mathrm{K}=\mathrm{A}+\mathrm{B} *[\mathrm{Re}]^{\mathrm{C}}
$$


where $\mathrm{A}, \mathrm{B}$ and $\mathrm{C}$ are three constant values $(\geq 0)$ specified by the user in such a way to reproduce the analytical trend of $\mathrm{K}$, with $\mathrm{K}=\mathrm{f}^{*} \mathrm{~L} / \mathrm{D}_{\mathrm{h}}$, being $\mathrm{L}$ the length of the FPS and $\mathrm{D}_{\mathrm{h}}$ the hydraulic diameter of the FPS.

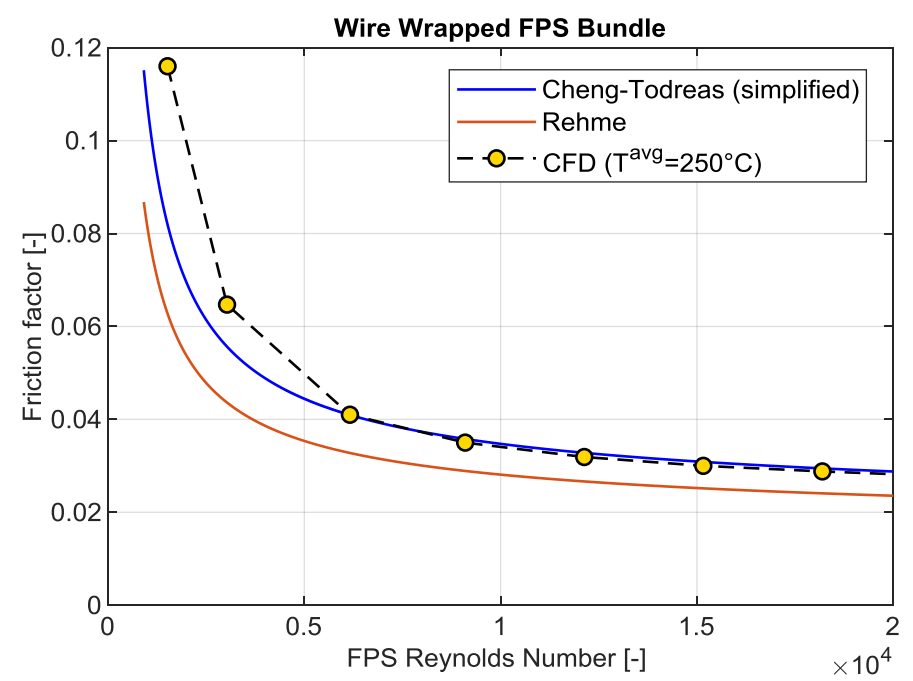

Figure 5. Wire wrapped friction factor correlation vs. CFD assessment

\subsection{Heat Exchanger}

The numerical modelling of the Heat Exchanger is essential to properly predict the average temperature of the LBE in the loop for all the investigated conditions. The blind phase of the benchmark exhibited average temperatures significantly lower compared to the experimental values, for all the three Tests. As shown in Figure 6 for Test-3, the simulated average temperature is far lower than the experimental value (deviates between 50 and $30 \mathrm{~K}$ from data), for the entire test duration.

Such an inconsistency has made mandatory a more detailed analysis of the previous HX "blind model". Therefore, a more accurate analysis of the overall heat transfer performance of the HX component was carried out. More specifically, the re-assessment focused on the thermal conductivity of the stainless-steel powder gap $(2.45 \mathrm{~mm})$. This latter, in fact, represents nearly the $50 \%$ of the total thermal resistance of the HX, hence largely affecting the overall heat transfer performances, and, consequently, the mean temperature of the loop. Therefore, based on more reliable experimental data (D. Rozzia et al., 2015), it was concluded that the value of the powder thermal conductivity, assumed for the blind simulations, was too high. The powder conductivity from D. Rozzia et al. (2015) is summarized in Figure 7, plotting the experimental correlations of the powder thermal conductivity as a function of the temperature for three increasing powder compactions indicated as RUN 0.0, 1.0 and 5.0 (dotted line). The plot reports also the thermal conductivity assumed in the blind RELAP5 simulations (blue line) and the updated one employed for the present post-test RELAP5 simulations (red line). The latter assumption is more consistent with the experimental data currently available, providing a more accurate modelling of the HX thermal performances and, in general, of the system behaviour. Concerning the assumption on the HX geometrical parameters (surfaces and thickness of the double wall tubes), these were used as specified in the drawings.

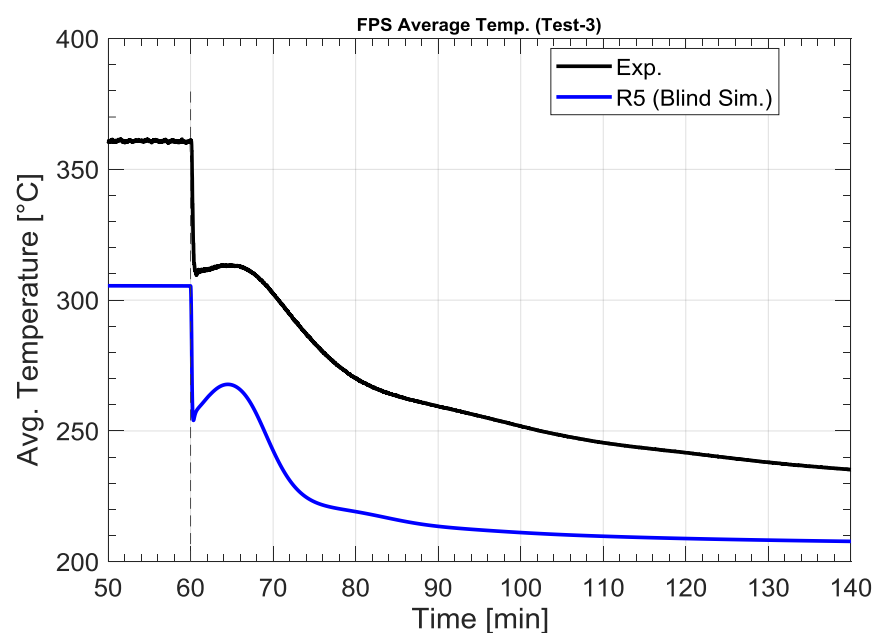

Figure 6. Comparison of the average loop temperature (blind simulation and experimental data, Test-3) 
Nuclear Engineering and Design 353 (2019) 110279, https://doi.org/10.1016/j.nucengdes.2019.110279

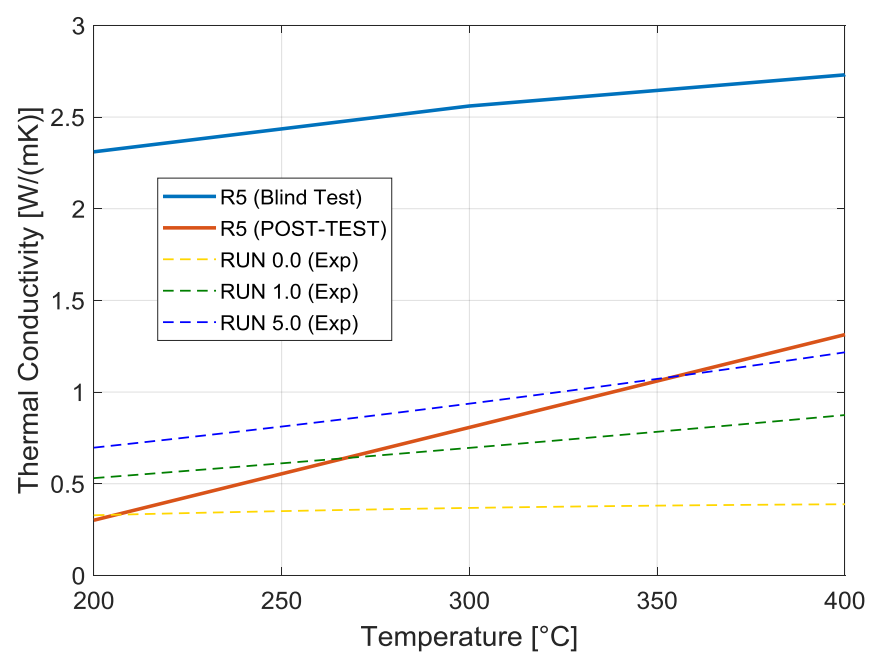

Figure 7. Stainless steel powder thermal conductivity 


\section{SYSTEM CODES USED BY THE PARTICIPANTS}

\subsection{University of Pisa model using RELAP5/Mod3.3}

The STH code employed at the University of Pisa (UniPi) was a modified version of RELAP5/Mod.3.3 code (RELAP5/Mod3.3 code manual, 2001). The modifications were carried out at UniPi to implement liquid metals ( $\mathrm{Na}, \mathrm{Pb}$ and LBE) among the code working fluids (G. Barone, 2013) and to choose specific convective heat transfer correlations for LMs (e.g. Seban and Shimazaki (R.A. Seban and T.T. Shimazaki, 1951) or Ushakov (P.A. Ushakov, 1977) for bare fuel bundle with triangular lattice). The thermodynamic properties of lead, LBE and sodium, for both saturation and single-phase conditions were implemented from Sobolev's work (V. Sobolev, 2011), together with their transport properties (i.e., thermal conductivity, dynamic viscosity and surface tension). These latter were included directly inside the FORTRAN source file of the code. The modified version of RELAP5/Mod.3.3 was qualified in previous works at UniPi, which focused, in particular, on the development of STH-CFD coupling tools (M. Angelucci et al., 2017; D. Martelli et al., 2017).

The RELAP5 model for NACIE-UP is mainly composed by several pipes and junctions reproducing the main rectangular loop. Other components are used to model the expansion vessel, the gas injection system and the secondary side of the HX. The cell length of the components varies from 0.05 (in the FPS and in the HX) to $0.665 \mathrm{~m}$ (in the cover gas region of the expansion vessel). Time-dependent volumes and time-dependent junctions are employed where necessary to set the boundary conditions of the specific simulation. A sketch of the model nodalization is depicted in Figure 8.

Pipes 100 and 110 represent respectively the pre-heated and the heated zone of the 19-pin FPS. The gas injection system is modelled through time-dependent volume 410 and time-dependent junction 405 , which injects argon in branch 125 , located at the experimental injection height. The injected gas flows in the riser (pipe 130) up to the expansion vessel (components 146, 148, 150, 152 and 156), where it separates from the LBE and flows towards branch 150. Time-dependent volume 320 allows to set the cover gas pressure boundary condition. The 7-tube heat exchanger is modelled with two pipes (186 and 190) for the low power and high-power sections, respectively. The secondary water side of the high-power section of the HX is modelled with pipe 590, time-dependent junctions 515 and time dependent volumes 510 and 599. The water side of the low power section of the heat exchanger was not modelled as it was not operated (empty) during the fundamental tests. The following active heat structures are employed to simulate:

- The power provided to the FPS active region (associated to the pipe 110);

- The power generated by the Thermal Flow Meter during its operation (associated with two volumes of pipe 210);

- The power transferred from the LBE primary side and water secondary side in the High-Power section of the HX (purple area in Figure 8). The transfer surfaces and the thermal resistances were modelled according to the geometrical and thermophysical data.

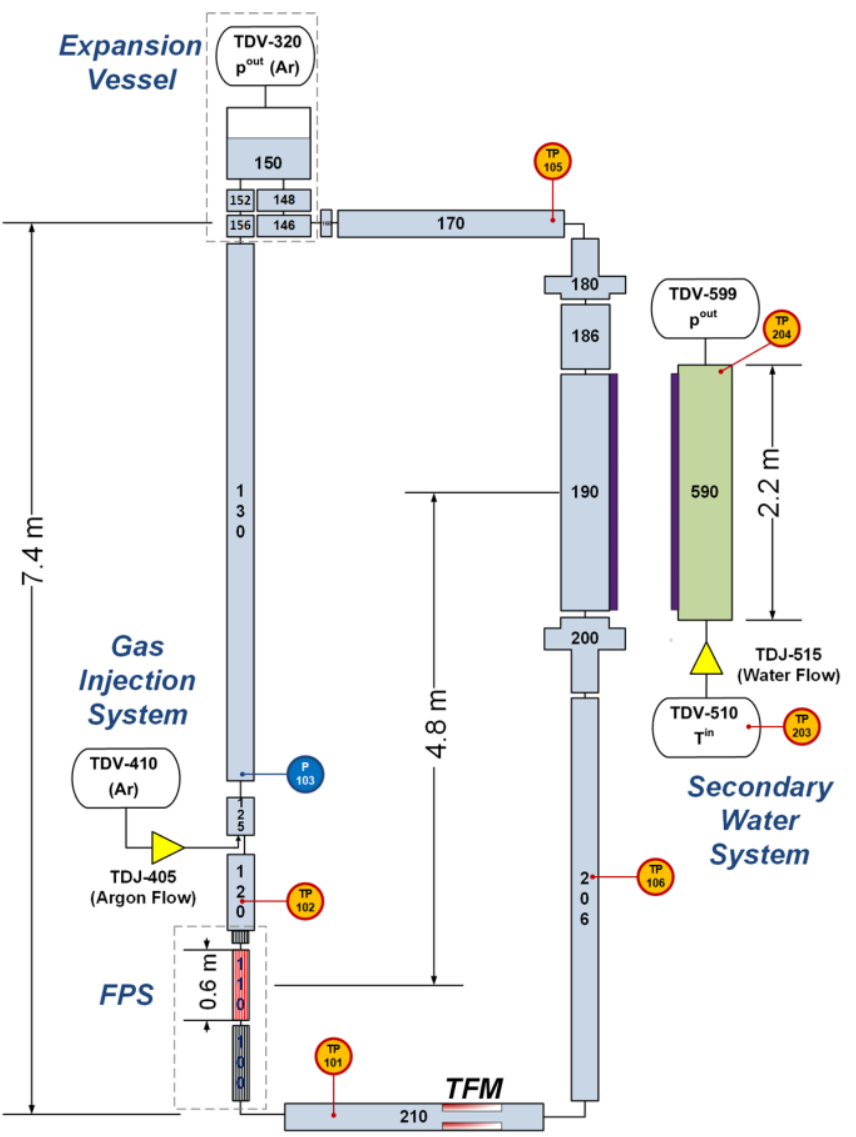

Figure 8. UniPi nodalization with RELAP5/Mod3.3 code

Additional passive heat structures are used to model the piping, the main flanges (HX and FPS flanges) and the thermal insulation, in order to account for the system thermal inertia and the heat losses toward the environment. For the loop main piping (2"'1/2, Sch.40), a pipe thickness of $5.16 \mathrm{~mm}$ is assumed, while the thickness of the thermal insulator around the main pipes is set to $100 \mathrm{~mm}$. The insulator thickness was reduced for the components around the FPS flanges in order to have the same outer diameter of the insulator with respect to the others. A thickness of $100 \mathrm{~mm}$ for the thermal insulator is also considered around the collectors of the heat exchanger. Similarly, the insulator thickness was reduced around the main flanges of the HX, maintaining a uniform outer diameter of the insulator around the main heat exchanger.

\subsection{ENEA model using CATHARE}

The "best-estimate" CATHARE code is a T/H system code employed for safety analysis of water reactor and management of accidental scenarios but also for the definition of operational procedures and for NPP licensing support. The CATHARE code treats the thermal-hydraulics of fluids mainly in one-dimensional motion flow with a two-phase model (liquid and gas). The CATHARE code has already been modified in the recent past to treat several other fluids (G. Geffraye et al., 2009). Within a Specific Topic of 
Cooperation between ENEA and CEA, the lead and lead-bismuth eutectic (LBE) thermodynamic properties (OECD/NEA Handbook, 2007) have been implemented (M. Polidori, 2010) and made available to the CATHARE users. The CATHARE code version used for the present blind simulations is the CATHARE V2.5_3 Mod 2.1.

The model nodalization of NACIE-UP facility for CATHARE system code is illustrated in Figure 9.

The complete natural circulation flow path of the primary circuit cooled by LBE is modelled mainly with one-dimensional elements (AXIAL), except the lower plenum, the expansion tank, and the heat exchanger inlet and outlet collectors modelled with zero-dimensional elements (VOLUME). The secondary side, cooled by water, is limited to the heat exchanger driven by boundary conditions. Due to CATHAREv2 limits in treating non-condensable gas dispersed in HLM, the pressure head contribution due to the argon injection is simulated with an externally imposed differential pressure, DPLEXT. The drawback of this assumption is that the hot leg column remains in single phase condition, affecting the mass of the hot column and hence the pressure field. Since there is not any representative experimental data that relates the argon injection to the LBE flowrate, once the pressure drops are calibrated in natural circulation condition (Test 3), the DPLEXT level is tuned to obtain the experimental LBE flowrate at every stationary state.

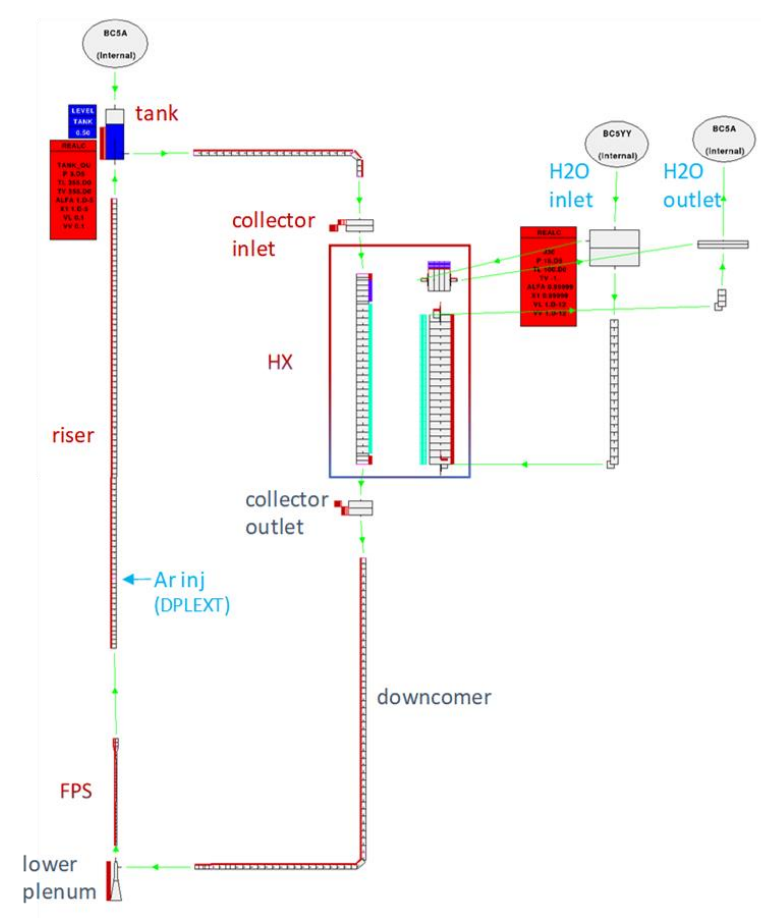

Figure 9. NACIE-UP nodalization for CATHARE code

The thermal conductivity of the steel powder in HX has been calibrated with experimental results to have comparable average temperatures in the loop. The thermal structures of the primary side are completely simulated: pipes, tank, mineral-resin insulation and the FPS. The detailed thermal structures of the secondary side are limited to the heat exchanger: interfaces between the primary and secondary sides, collector's flanges, tube grids, shell wall and mineral-resin insulation. The other secondary side parts shown in the scheme are considered as adiabatic and they do not represent the real layout of the secondary side.

\subsection{GRS model using ATHLET}

The thermal-hydraulic system code ATHLET (Analysis of THermal-hydraulics of LEaks and Transients is being developed by the Gesellschaft für Anlagen- und Reaktorsicherheit (GRS) for the analysis of the whole spectrum of leaks and transients in light water reactors (PWRs and BWRs) without core damage, small modular reactors (SMR) as well as in GEN-IV reactors with helium or liquid metal coolants ( $\mathrm{Pb}, \mathrm{LBE}, \mathrm{Na})$. The main code features are the advanced thermal-hydraulics, the modular code architecture, the separation between physical models and numerical methods, the pre- and post-processing tools, and the portability to the prevalent computer platforms. Interactive code control and visualization of simulation results is enabled by the GRS analysis simulator ATLAS. 
The numerical model of the NACIE-UP facility is shown in

Figure 10. The primary side of the loop consists of the thermo-fluid object (TFO) HEATER which is coupled with the heat conduction objects (HECU) PIN1 representing the 19 fuel rods. Above the TFO HEATER the RISER is implemented with the argon injection from the side by the object FILL. After the RISER the LBE flows in the TFO VESSEL and in the vessel downwards (TFO DC BOT) and then sideward into the horizontal pipe LINK2. Additionally, there is a time dependent volume above the VESSEL as boundary condition for the system, e.g. the gas flow.

The heat exchanger section is flanged at the end of the bend of LINK2. First, there is the branch HX_IN that is the inlet for the 7 pipes (TFO HX) of the heat exchanger and the outlet is again modelled with the branch HX OUT. The secondary side of the heat exchanger is modelled by the TFOs WATSEC_IN for the inlet, HXSEC that is coupled via the HECU STR_HX, and WATSEC_OUT for the outlet, which is finally coupled with the time dependent volume HXTDV. All structures are insulated (shattered objects) using the given material properties of the insulation. The outer side of the insulation is coupled via a HTC to the environment, which has a fixed temperature of $25^{\circ} \mathrm{C}$. The gas injection is modelled as an argon mass source (without momentum) at the elevation of the injection line.

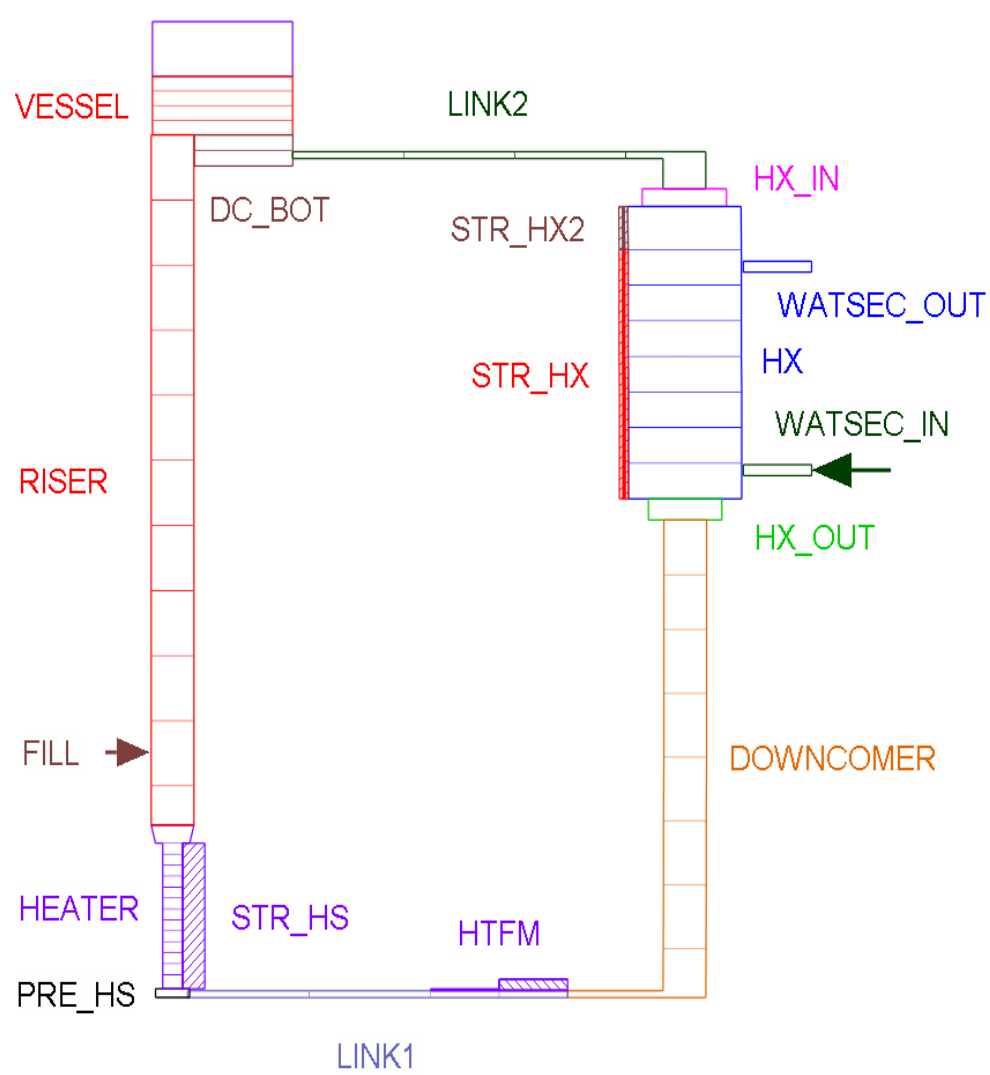

Figure 10. NACIE-UP nodalization whit ATHLET code

For the post-test simulations of the NACIE-UP tests with ATHLET four issues were solved. First, the additional heat input by the flow meter was implemented and optimized to predict the thermal behaviour before and behind the flow meter as close as possible to the experiment. Second, the model of the heat exchanger was improved: the two sections were modelled in detail to represent the high power and the low power heat exchanger section. Third, the heat transfer properties especially the thermal conductivity of the steel powder of the heat exchanger tubes were improved on the base of the data shown in Figure 7. Additionally, the impact of the friction factor prediction was investigated and improved, as suggested in section 3.1. For the HX also the initial and boundary conditions were adjusted to assess the measured data of the pre-test experiments.

\subsection{University of Rome model using RELAP5-3D}

The University of Rome "La Sapienza" (UniRo) activity in the NACIE-UP Benchmark was carried out using RELAP5-3D" (RELAP5-3D Code Manual, 2013) system thermal-hydraulic code (Version 4.3.4). Its validation was accomplished through a series of experimental tests for the evaluation of the code capability to simulate a two-phase system with liquid lead-bismuth eutectic and gas, both for steady state conditions and during transients from natural circulation to gas-enhanced circulation and vice-versa.

The scheme of the nodalization (Figure 11) is obtained improving the previous NACIE model (Narcisi et al., 2019) and it consists in a one-dimensional model of several pipes and junctions connected to each other in such a way to build a truthful simulation of the different parts of the loop. The model is composed by 186 hydrodynamic volumes and 184 junctions with a mesh size comprised in a range between $0.09 \mathrm{~m}$ and $0.18 \mathrm{~m}$. The NACIE-UP model is composed by the following parts: the FPS (PIPE 001, active length represented in red), its outlet pipe (PIPE 003), the riser (PIPE 005), the expansion tank (PIPE 103 and PIPE 007), the HX primary side (PIPE 011), the HX low and high power secondary side (PIPE 203 and PIPE 208, respectively), the downcomer (PIPE 013) and the two horizontal legs (PIPE 009 and PIPE 015).

The TMDPVOL 101 and TMDPJUN 102 assure the argon injection in the middle of the riser, while the TMDPVOL 105 on the top of the expansion tank represents the outlet of the gas. Concerning the HX secondary side, the low power section has the TMDPVOL 201, which imposes the temperature and pressure of the water, while the TMDPJUN 202 fixes the water flow requested; the TMDPVOL 205 represents the outlet of the water. At the same way, in the high power section the TMDPVOL 206 imposes the temperature and pressure of the water, the TMDPJUN 207 fixes the water flow rate; the TMDPVOL 210 represents the outlet of the water. 
The division in volumes of the loop has been carried out in order to consider the correct position of the bubble tubes and the thermocouples located along the loop. Concerning the heat structures, a thermal coupling has been simulated:

between the active length of the FPS and the LBE in the primary side (HS001);

between the LBE of the primary side and the water in the secondary system (HS002);

between the primary system and the external environment.

The 19 pins of the FPS and the seven pipes of the HX have been simulated with a single equivalent heat structure respectively. All the differences of thickness in the insulation due to the flanges have been considered in the heat structures nodalization. An additional heat structure (HS 051) has been added on the lower part of the loop in order to consider the power supplied by the thermal flow meter FM-101. A further heat structure (HS 052) has been added upstream the FPS active region to simulate the power released to the LBE before the active length $(\sim 7 \%)$.

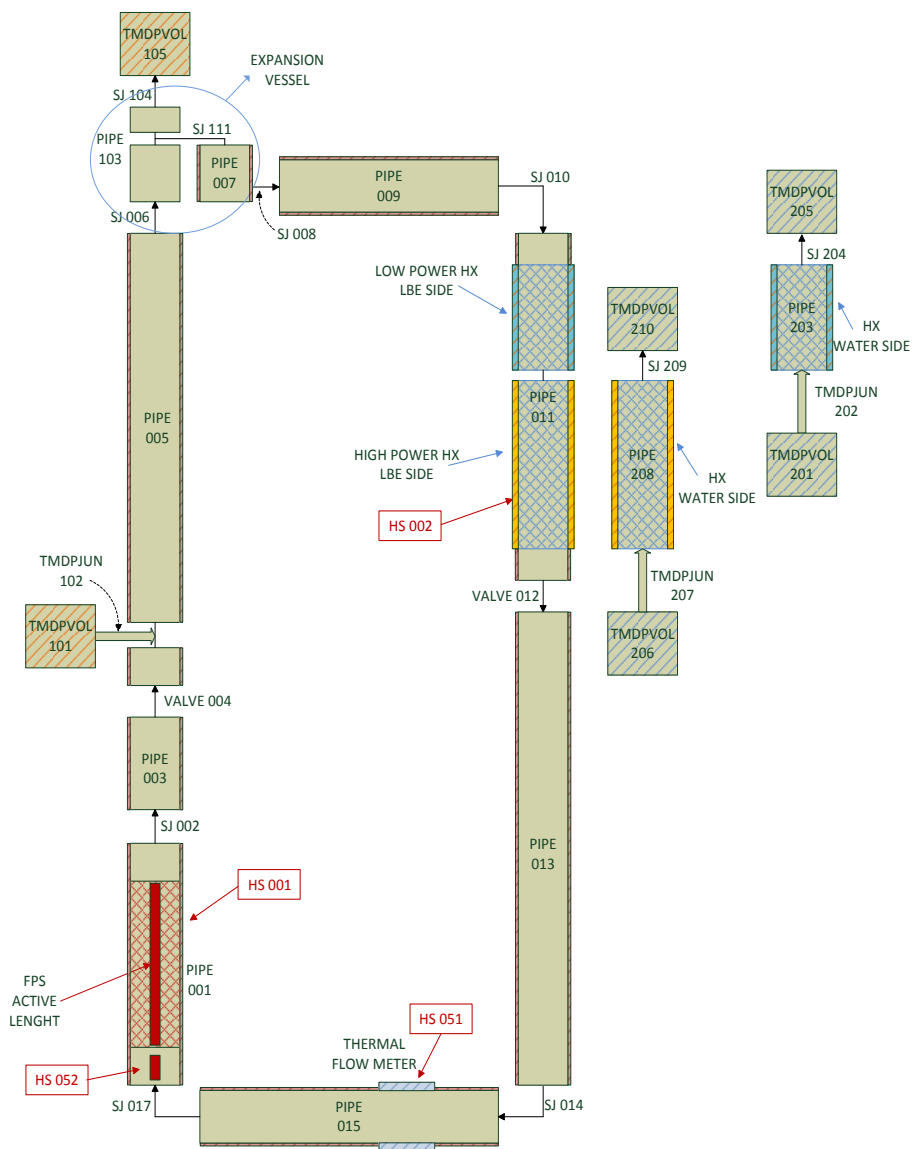

Figure 11. NACIE-UP nodalization with RELAP5-3D code

The singular pressure drops along the circuit are introduced for changes of directions and sudden area changes inside the expansion tank, and the FPS inlet-outlet sections (Idelchik I. E., 2003). The evaluation of the K resistance coefficient for the FPS grid has been made using the Rehme correlation (OECD/NEA Nuclear Science Committee, 2015).

The friction factor for the wire-wrapped rod bundle has been evaluated with the detailed Cheng and Todreas correlation (Chen et al., 2014). RELAP5-3D have the possibility to insert only two correlations (one for laminar zone and one for turbulent). The difference is the transition zone: in RELAP5-3D a linear interpolation from the laminar friction evaluated with $\mathrm{Re}=2200$ and the turbulent friction with $\mathrm{Re}=3000$ is imposed. The differences among the Cheng and Todreas correlations and the implemented friction factor are presented Figure 12.

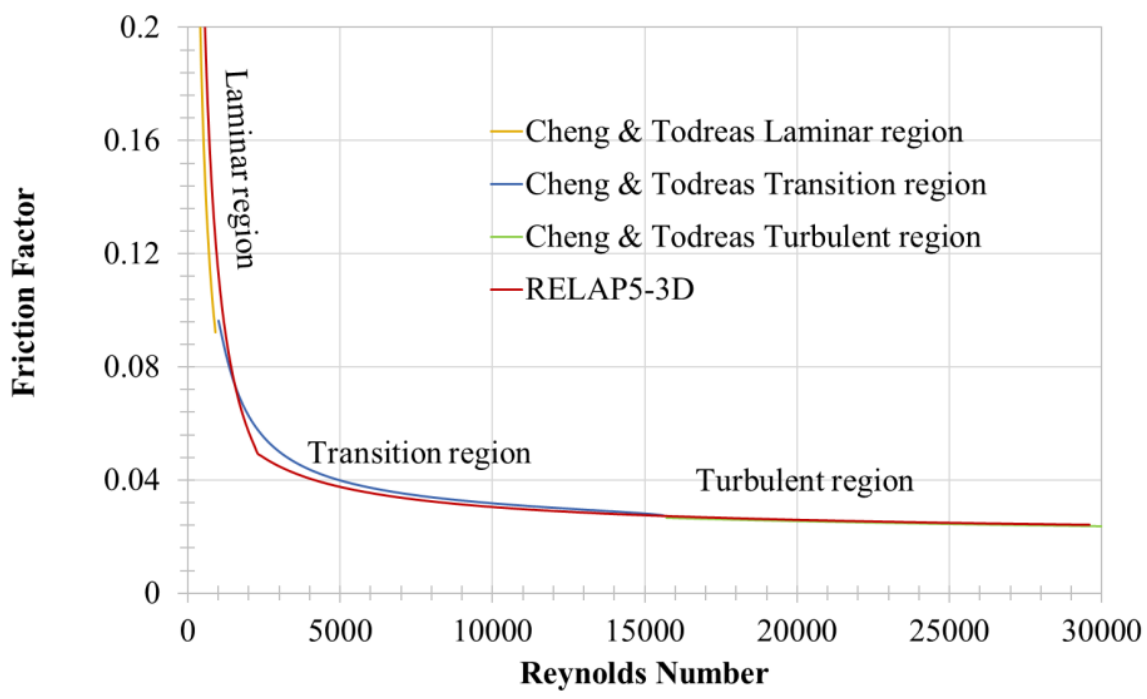

Figure 12. Friction factor implemented in UniRo model

Concerning the heat transfer model in the rod bundle, the correlation of Kazimi and Carelli for liquid metals has beer used (C. B. Davis A. S. Shieh, 2000).

During the Post-Test activity, a sensitivity analysis has been carried out in order to evaluate the influence of the AIS] 
316L powder thermal conductivity on the thermal-hydraulic performances of the heat exchanger. The initial correlatior assumed for the blind simulations from D. Rozzia et al. (2015) has been replaced in the post-test activity with a new ont reported in Figure 13 and similar to the correlation introduced in Figure 7.

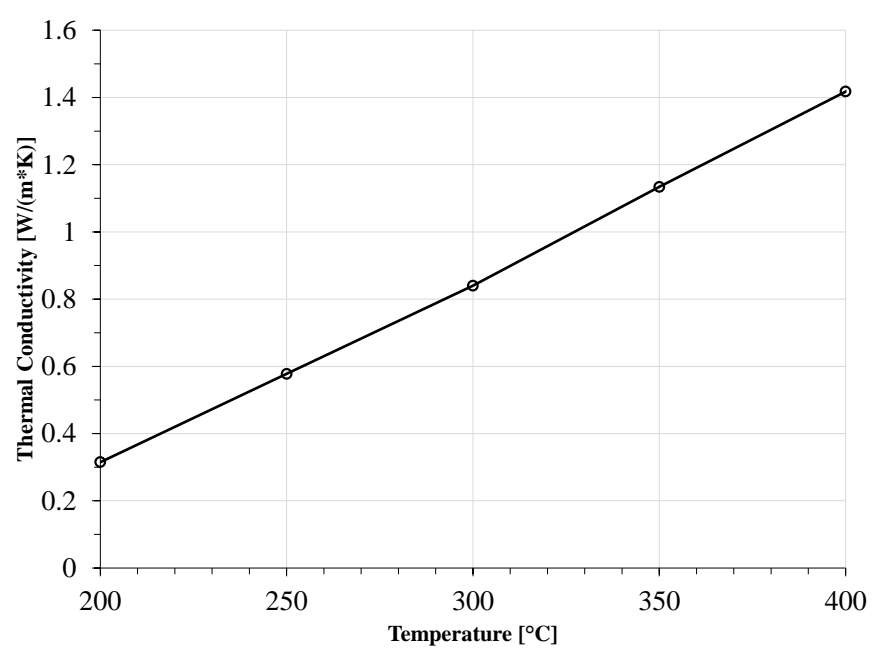

Figure 13. Stainless steel powder thermal conductivity

\section{THE NACIE-UP STH CODE BENCHMARK}

\subsection{Overview}

The stand-alone code benchmark consists in blind simulations of a set of experiments performed on the NACIE-UP facility reproducing three transients (operative and accidental) relevant for HLM nuclear systems. The three tests are:

1. Gas flow transition (Test-1). It consists in a reduction of the injected argon flow from 20 to $10 \mathrm{Nl} / \mathrm{min}$, maintaining the FPS power to a constant level of $50 \mathrm{~kW}$. The water temperature at the inlet of the $\mathrm{HX}$ is set to $170^{\circ} \mathrm{C}$ and the pressure at 16 bar, while the water mass flow rate was maintained constant to the initial value of $10 \mathrm{~m} 3 / \mathrm{h}$ during the whole test.

2. Power transition (Test-2). It consists in a FPS power reduction from 100 to $50 \mathrm{~kW}$ (decreasing rate $1 \mathrm{~kW} / \mathrm{s}$ ) maintaining the injected argon flow to $18 \mathrm{Nl} / \mathrm{min}$. The water temperature at the inlet of the $\mathrm{HX}$ is set to $170^{\circ} \mathrm{C}$ and the pressure at 16 bar, while the water mass flow rate was maintained constant at $6.6 \mathrm{~m}^{3} / \mathrm{h}$.

3. Protected Loss of Flow Accident, PLOFA (Test-3). This kind of transition reproduces a protected loss of flow caused by the removal of the gas lift enhancing the loop circulation and the establishment of natural circulation. In particular, it consists in a decrease of the FPS power from 100 to $10 \mathrm{~kW}$ (decreasing rate of $10 \mathrm{~kW} / \mathrm{s}$ ) and the complete deactivation of the injected $\operatorname{argon}$ flow from 20 to $0 \mathrm{Nl} / \mathrm{min}$. In this case, the water inlet conditions are identical to those of Test-1.

The three tests nominal boundary conditions (BC) are shown in Figure 14 together with the experimental time trends of some BC data.

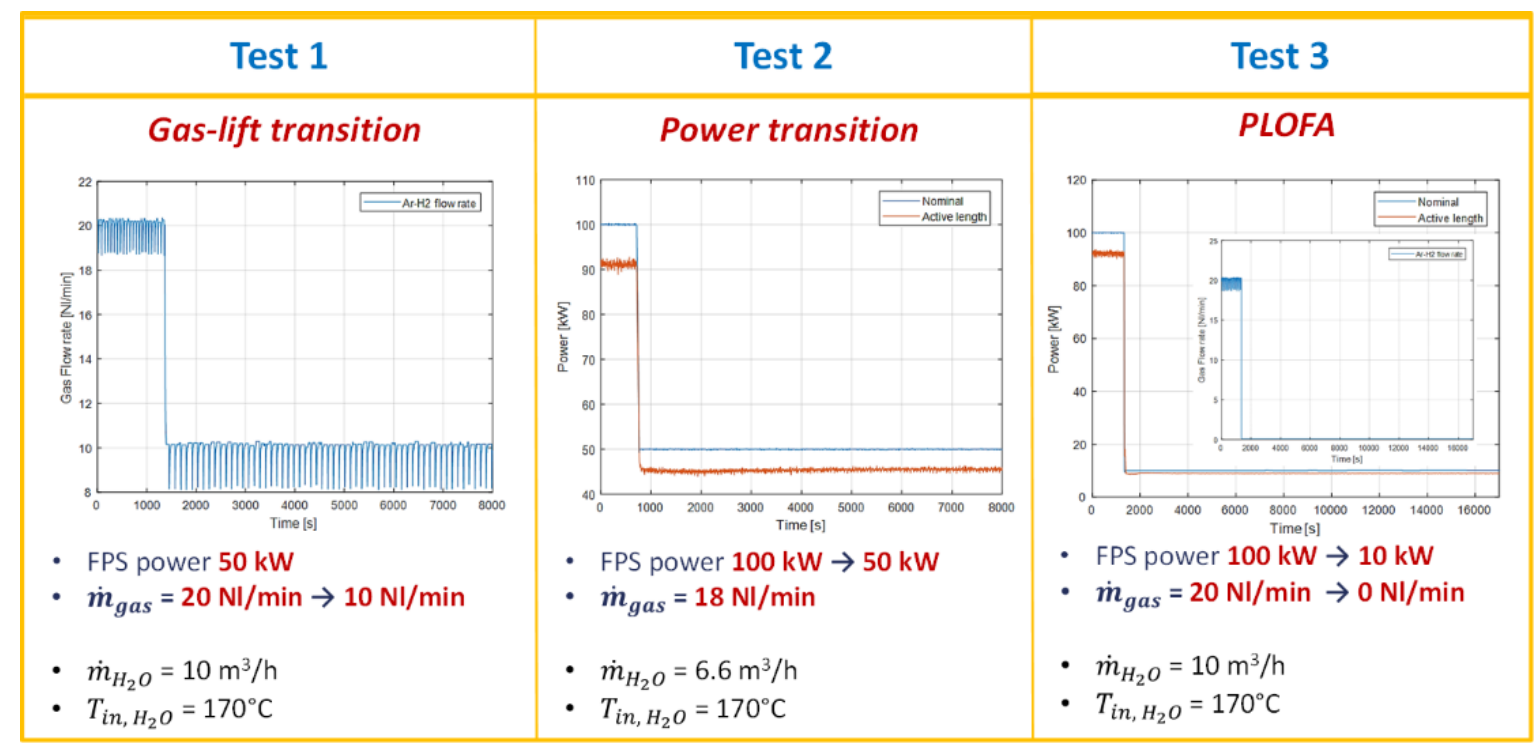


Figure 14. Boundary conditions of the three benchmark tests

Each test is characterized by two steady-state conditions: prior (S.St-1) and subsequent (S.St-2) the transition event. The transition event in the simulations was set after about 60 minutes from the beginning of the simulation (in S.St-1 conditions).

The primary side is filled with LBE up to the high-level sensor of the expansion tank with a cover gas (argon) pressurized at 1.4 bar. The secondary side, filled with water at $16 \mathrm{bar}$, is operated with an inlet temperature of $170^{\circ} \mathrm{C}$ and a total volumetric water flow rate of 6.6 or $10 \mathrm{~m} 3 / \mathrm{h}$ depending on the power level. Only the high-power section of the HX is operated during the tests.

A set of integral physical parameters has been selected based on their relevance for thermal-hydraulic characterization of the facility. These thermal-hydraulics variables were acquired during the experimental campaign to be used in the post-test analysis. The whole set of transducers and their location in the NACIE-UP circuit are illustrated in Figure 15, while

Table 1 summarizes only the parameters of interest for the actual discussion.

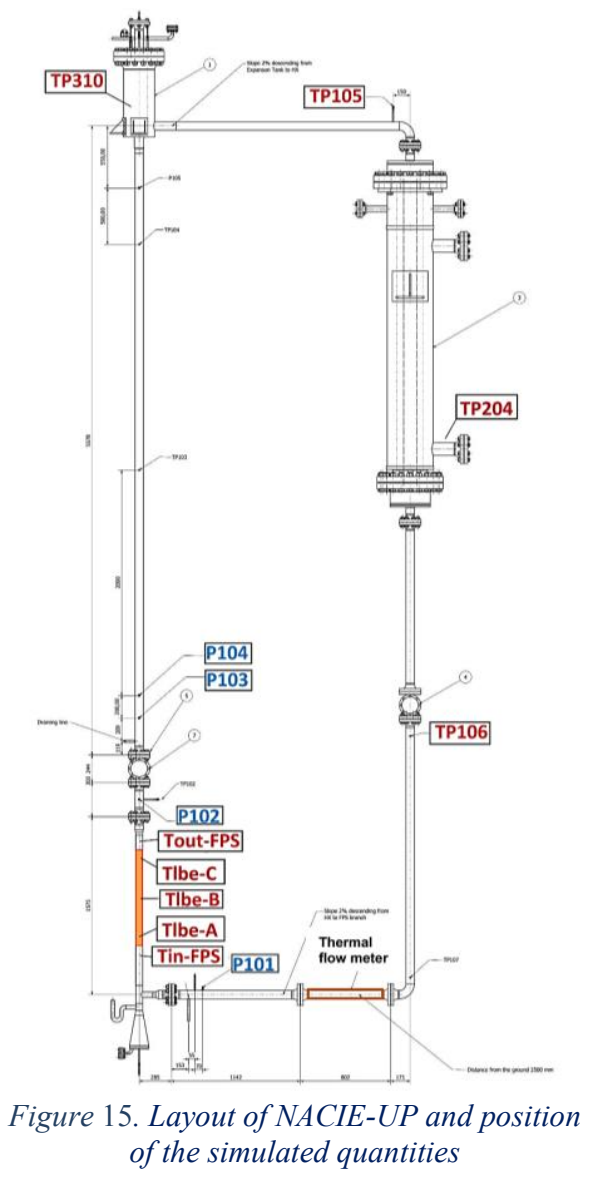

Table 1. Parameters for the STH codes benchmark

\begin{tabular}{ccc}
\hline Parameter & Loop position & Variable \\
\hline LBE mass flow rate & Entire Loop & LBE-MFR \\
\hline \multirow{2}{*}{ LBE Temperatures } & FPS inlet & T101 \\
& FPS outlet & Tout-FPS \\
& HX inlet & TP105 \\
& HX outlet & TP106 \\
\hline \multirow{2}{*}{ Water Temperature } & HX secondary side & TP204 \\
\hline \multirow{2}{*}{ outlet } & P102 \\
\hline \multirow{2}{*}{ Loop Pressure } & Downstream the & \\
\hline
\end{tabular}

\subsection{Test-1: Gas flow transition}

The LBE mass flow rate in the circuit is reported in Figure 16. Before the argon flow reduction, the experimental value of the LBE mass flow rate is about $3.8 \mathrm{~kg} / \mathrm{s}$. The values of LBE flow rate, related to this steady state condition (S.St.-1), calculated by ENEA, UniRo and UniPi is in very good agreement with the experimental data, while GRS predicted a value of about $4.2 \mathrm{~kg} / \mathrm{s}$, indicating an underestimation of the pressure drops along the circuit. The ENEA numerical model uses a momentum source to reproduce the lift effect of the injected argon in the riser and to replicate in best way the two steady mass flow rate values and this results in a very good approximation of the LBE mass flow rate time trend. The reason for this model approach is that the user was not been able to reach any numerical convergence when the gas is injected in liquid metal. The issue would have been overcome, in some way, in the presence of a reliable preliminary test that relates argon injection and mass flowrates, and in turn with the momentum to be applied in the CATHARE nodalization, but the test given for the model preparation was not representative of the facility state, at the time of experimental campaign.

The gas lift reduction from 20 to $10 \mathrm{Nl} / \mathrm{min}$ brings the system to a new steady state (S.St. -2 ) characterized by a LBE flow rate of $3.1 \mathrm{~kg} / \mathrm{s}$. In this new steady state condition both ENEA and UniRo simulations predict values that are in perfect agreement with the experimental data. GRS predicted this LBE mass flow rate with an overestimation of about $10 \%$ that is in the same direction with 
what was obtained in S.St.-1; UniPi, vice versa, underestimates the experimental value by $10 \%$ despite that the S.St.-1 value was well captured.

In the transition phase, from 60 to $70 \mathrm{~min}$, similar mass flow time trends are obtained by all the participants which are in agreement with the experimental trend. More specifically, immediately after the gas flow transition, a sudden LBE flow reduction to a minimum value occurs, followed by an oscillating trend that quickly dumps to the new equilibrium value. This behaviour can be physically interpreted assuming the gas reduction as a prompt break for the LBE circulation, followed by the rebalance of the buoyancy effects leading to a typical damped oscillating system behaviour.

The LBE inlet and outlet temperatures in the FPS and HX are reported in Figure 17 and Figure 18 respectively, showing a similar time history for the outcomes of all the participants. The results obtained by ENEA show the best agreement with the experimental results due to the accurate estimation of the LBE mass flow rate, linked to their specific numerical model. In all the cases at the transition time $(t \approx 60 \mathrm{~min})$ the FPS outlet temperature (Figure 17.b) exhibits a sudden increase which propagates with a certain delay, a smoother shape and a reduced value (due to the thermal losses), to the HX inlet (Figure 18.a). Here, the outlet temperature shows a decreasing trend from the previous steady state before reaching the new steady state (transient time $\sim 15$ min). The same trend is observed at the FPS inlet (Figure 17.a) except for a small peak attributed to the effect of the thermal flow meter (TFM) after the flow reduction.

In steady state conditions, the LBE temperature differences, $\Delta T$, through the FPS and the HX, are determined by the mass flow rate and the FPS power, while the average temperature $\left(T_{a v g}\right)$, is related to the secondary inlet water conditions (mass flow rate, pressure and temperature) and to the HX overall heat transfer coefficient. This latter (given the HX geometry) strongly depends on the thermal parameters (e.g. powder thermal conductivity and convective heat transfer coefficient for both water side and LBE side), adopted by each participant to model the HX component, and leads to the differences for the loop average temperature. The mass flow reduction induces a rapid increase of both the FPS $T_{\text {out }}$ (prompt) and the HX $T_{\text {in }}$ (delayed), while a smoother temperature decrease is observed for both FPS $T_{\text {in }}$ and HX $T_{\text {out }}$. The temperature transient reproduced by each participant follows the same mass flow rate oscillating trend before achieving the new steady state.

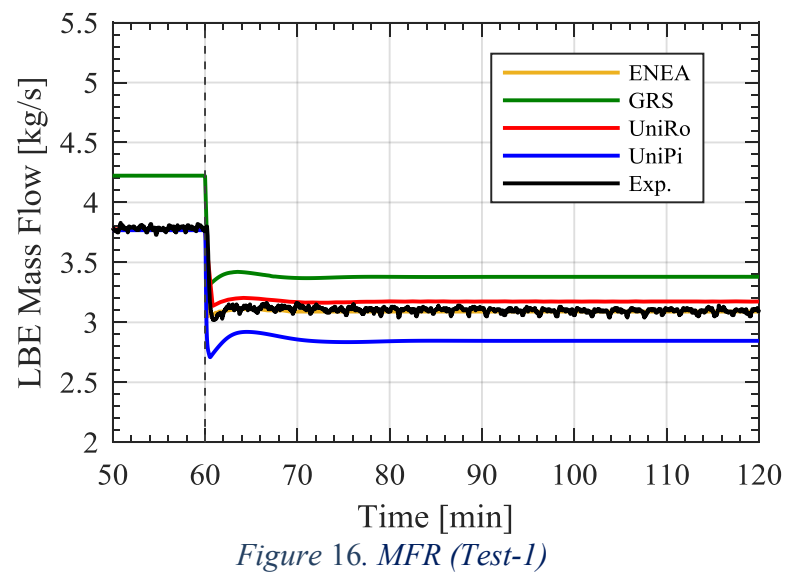

The inlet temperature of the FPS, $T_{F P S, i n}$, is generally higher than the outlet temperature of the HX, $T_{H X, \text { out }}$, due to the effect of the thermal flow meter, TFM, positioned between the two components in the lower horizontal section. In fact, the TFM operation foresees the heating of the LBE flow passing through it, providing to the flowing LBE an additional external power (1-2 kW). On the contrary, the thermal losses associated to the riser and to the upper horizontal piping, cause the $\mathrm{HX}$ inlet temperature, $T_{H X, i n}$, to be a few degrees lower than the FPS outlet temperature, $T_{F P S \text {,out }}$.

Figure 19.a reports the secondary water outlet temperature in the HX, showing essentially a good agreement among the participants results. The slight discrepancies may be related to the removed HX power and the assumption on the water density.

For what concerns the pressure inside the loop, Figure 19.b reports the values of pressure downstream the FPS. The pressure values obtained by the participants are quite different from each other. The results of ENEA and UniPi are in better agreement with the experimental data. The discrepancies obtained by some participants (mainly GRS and UniRo) can be ascribed to various factors as the differences in the choice of the vertical nodalization, the level inside the expansion tank and the loop temperatures. The LBE properties and the implemented heat transfer correlations in the codes also differ among the participants. Despite these discrepancies, the pressure response is quite similar among the numerical models, exhibiting a sudden jump after the gas transition that can be attributed to the riser density increase immediately after the reduction of the gas injection. 

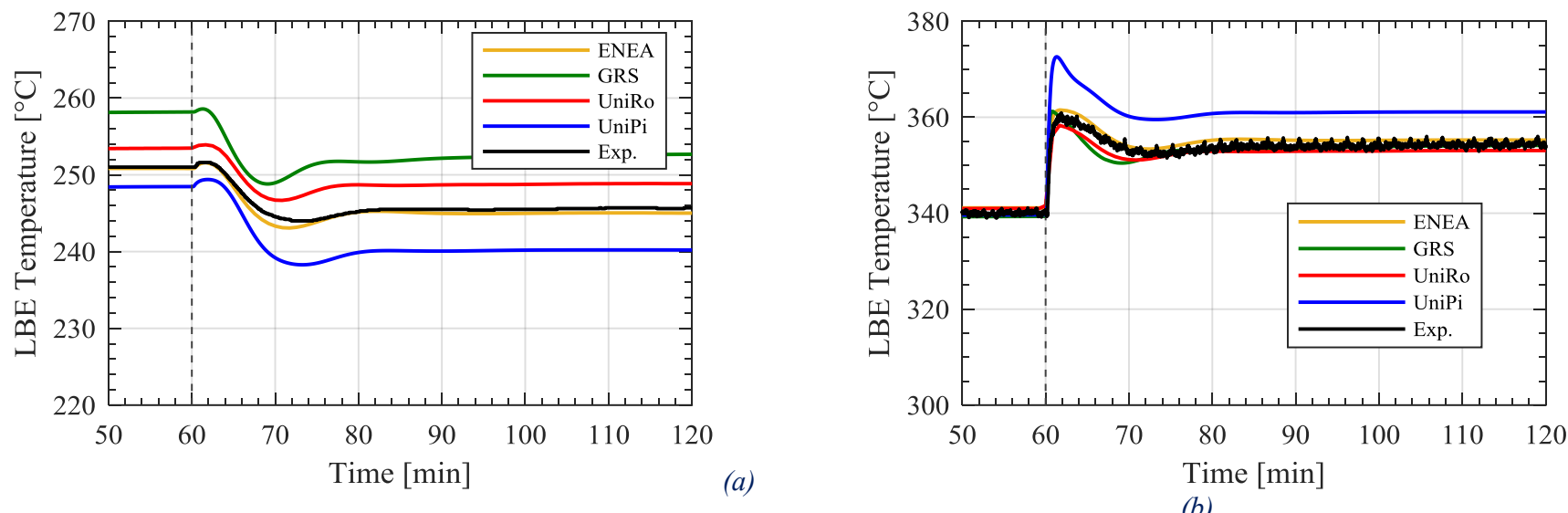

Figure 17. LBE temperature at the FPS inlet (a) and outlet (b); (Test-1)
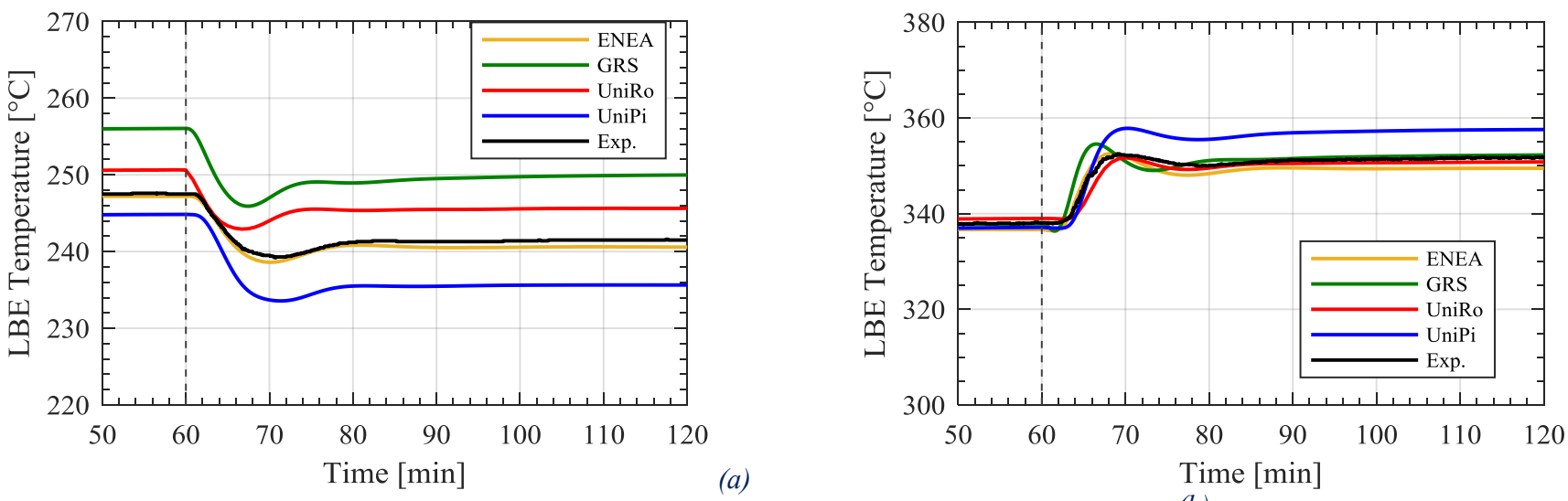

Figure 18. LBE temperature at the HX outlet (a) and inlet (b); (Test-1)
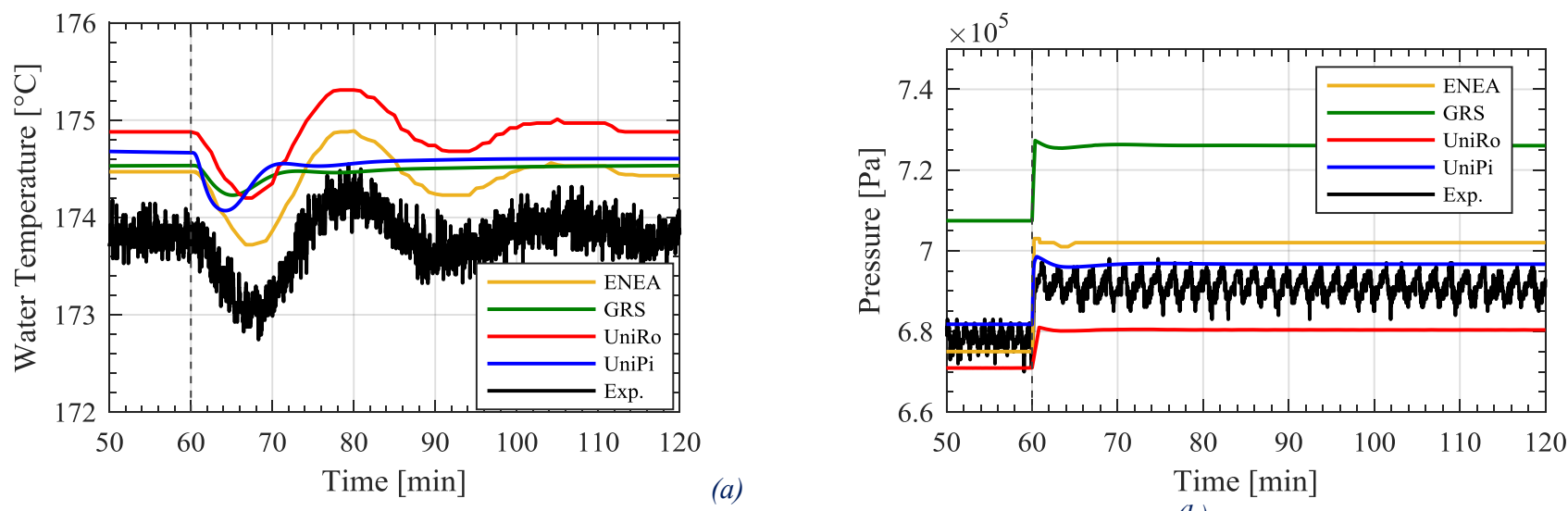

(b)

Figure 19. Water temperature at the HX outlet (a) and pressure downstream the FPS (b); (Test-1)

\subsection{Test-2: Power transition}

In Test-2 the gas flow is kept constant and the mass flow rate reduction after the simulated transient (see Figure 20) is exclusively a consequence of the FPS power reduction. For each participant, the mass flow rate before the transition is found in the range of 4.0 and $4.5 \mathrm{~kg} / \mathrm{s}$ with on overestimation of the calculated data respect to the experimental value of maximum $10 \%$. After the transition, the flow reduction, due to the reduction of the thermal buoyancy effect, is of about $0.4 \mathrm{~kg} / \mathrm{s}$. The mass transition trend appears almost similar for all the participants and all the numerical models are able to capture the LBE mass flow rate reduction.

The LBE inlet and outlet temperatures in the FPS and HX are depicted respectively in Figure 21 and Figure 22, showing the same decreasing trend. In fact, the power transition from 100 to $50 \mathrm{~kW}$ causes the loop mean temperature to decrease. GRS found an LBE temperature greater than the experimental value inside both cold and hot leg for the S.St.-1. In the UniRo simulation, before the transient, the temperatures obtained at the FPS outlet and HX inlet match the experimental data, while at the FPS inlet and HX outlet the temperatures are higher than the experimental values, due to the overestimation of the LBE mass flow rate. ENEA and UniPi obtained a lower temperature value in the cold leg for the S.St.-2. 


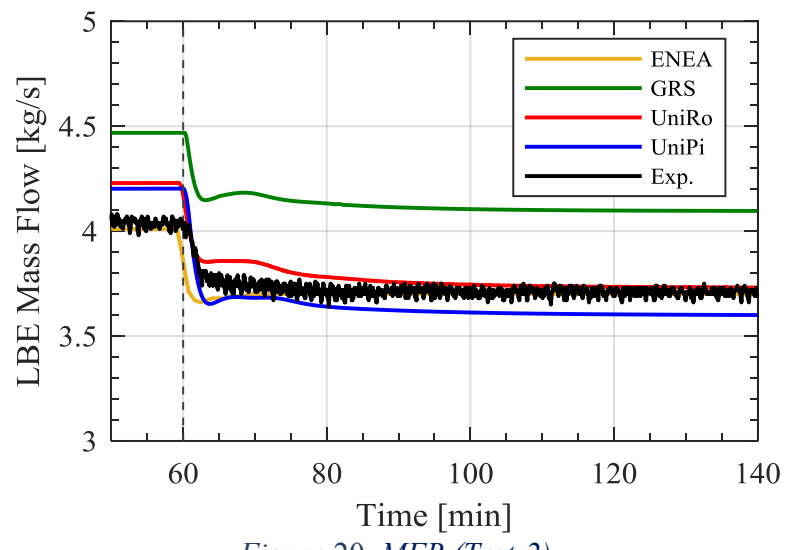

Figure 20. MFR (Test-2)

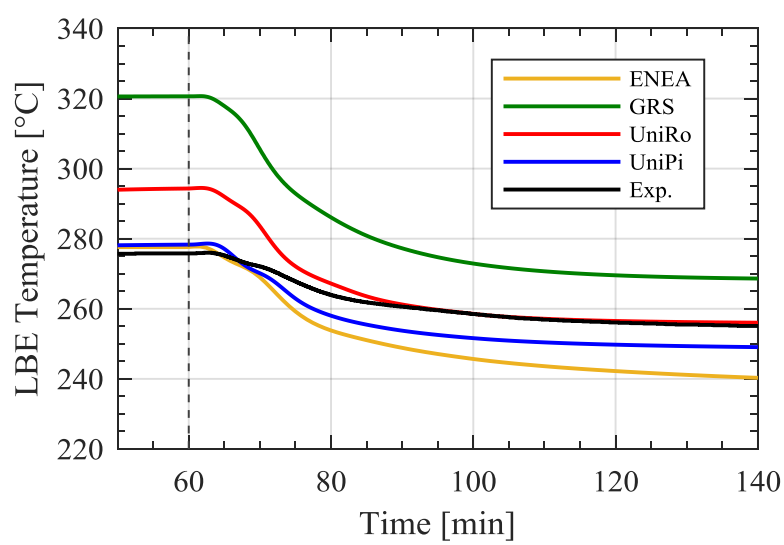

(a)

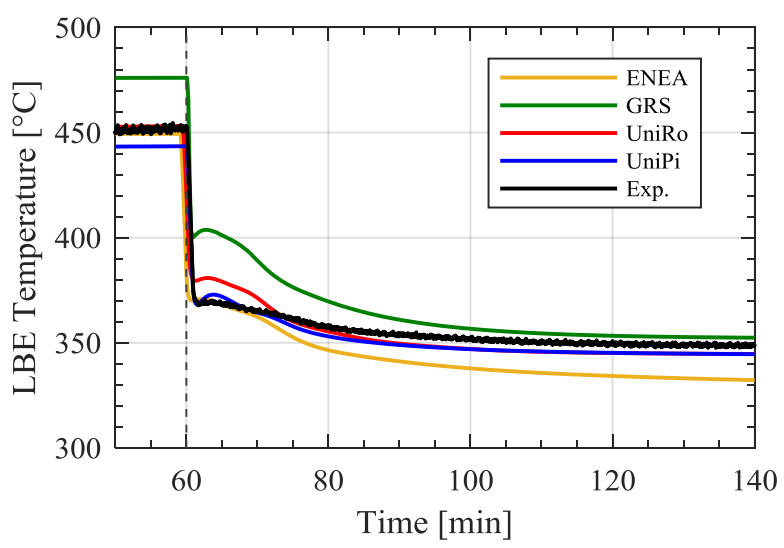

(b)

Figure 21. LBE temperature at the FPS Inlet (a) and outlet (b); (Test-2)

Although the mean temperatures $T_{\text {avg }}$ are different among the participants, due to the differences in the HX modelling, the temperatures' decreasing trend is similar and the time required to reach the new stationary temperatures varies slightly. The considerations made for Test-1 are similar for Test-2. The FPS outlet temperature (Figure 22.b) exhibits a sudden decrease immediately after the power transient. The temperature decrease propagates, with a smoother trend and reduced value (due to thermal losses), along the circuit flow path towards the HX inlet (Figure 23.a).

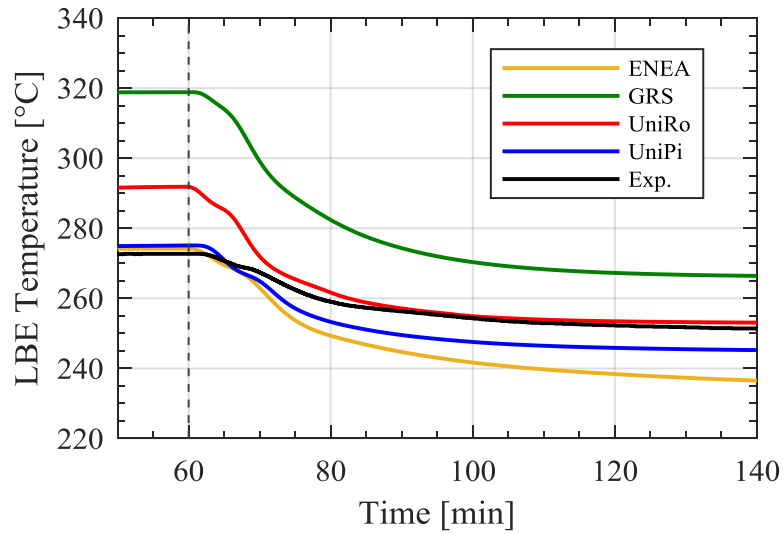

(a)

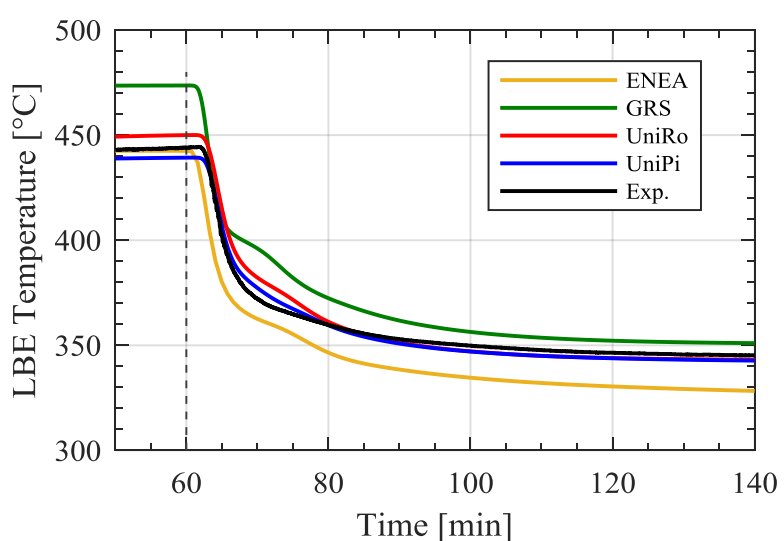

(b)

Figure 22. LBE temperature at the HX outlet (a) and inlet (b); (Test-2)

\subsection{Test-3: Protected Loss of Flow Accident, PLOFA}

The LBE flow rate, depicted in Figure 23, goes from a gas lift circulation regime, with an experimental value of $4.3 \mathrm{~kg} / \mathrm{s}$ and with values predicted by the $4 \mathrm{STH}$ codes inside the range $4.3-4.6 \mathrm{~kg} / \mathrm{s}$, to an exclusively natural circulation regime with an experimental value of about $1 \mathrm{~kg} / \mathrm{s}$ and calculated values in the range of $\pm 10 \%$ of this value. The mass flow transient trends are almost similar for all the participants and in agreement with the experimental trend. Immediately after the gas circulation is deactivated, the LBE flow undergoes a sudden reduction, followed by an oscillatory trend, of about 15 min, just like for Test-1. 
The LBE inlet and outlet temperatures in the FPS and HX are reported respectively in Figure 23 and Figure 24 . As for the previous tests, the temperature trends during the transition are similar among all participants. GRS for the S.St.-1 found a LBE temperature of about $30-40^{\circ} \mathrm{C}$ greater than the experimental value inside both cold and hot leg. Anyway, when natural circulation condition was obtained, all participants predicted LBE temperatures inside the loop which are in good agreement with the experimental values. At the transition $(t \approx 60 \mathrm{~min})$, the FPS outlet temperature (Figure 24.b) exhibits a sudden decrease followed by a smooth increase and then again a slow decrease (oscillating trend) to the stationary minimum value, that is reached in more than 180 min. In general, the loop temperature transition slope varies accordingly to the dynamic and thermal inertia assumed to model the system (LBE total mass, pipe thickness and heat losses), therefore the different behaviour respect to the experimental trends support the hypothesis that in all the numerical models both of them were underestimated in the numerical models.

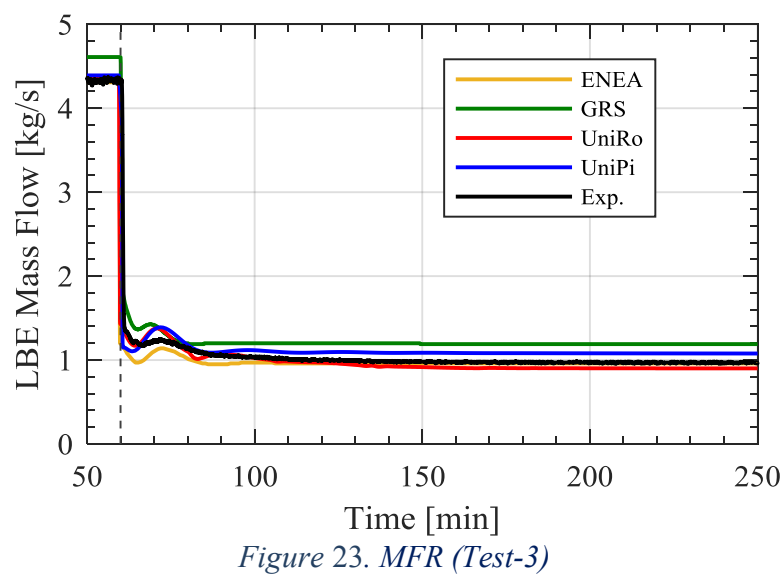

As for the previous tests, the FPS outlet temperature propagates through the loop with a smoother shape and lower value (due to the thermal losses), as shown for the HX inlet temperatures (Figure 25.b). The HX LBE outlet temperature, shown in Figure 25.a, propagates to the FPS inlet temperature (Figure 24.a) with a few degrees Celsius increase, caused by the thermal power used for the TFM. The small temperature peak observed immediately after the transition, highlights the presence of the TFM.

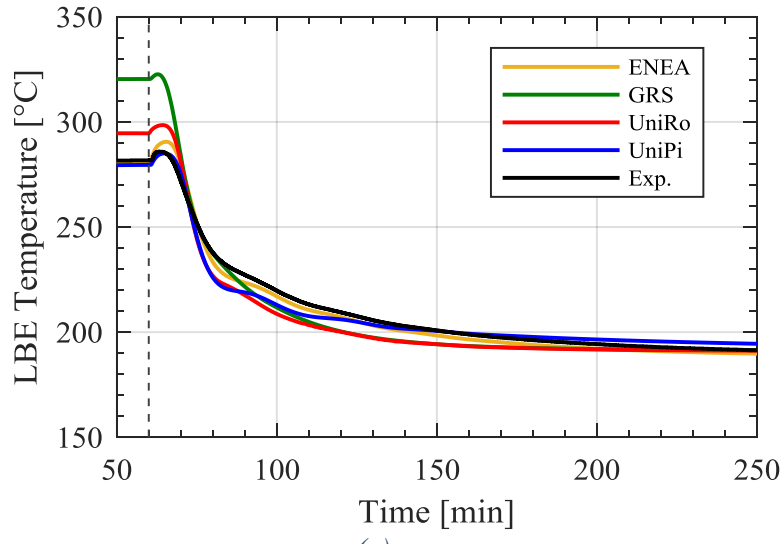

(a)

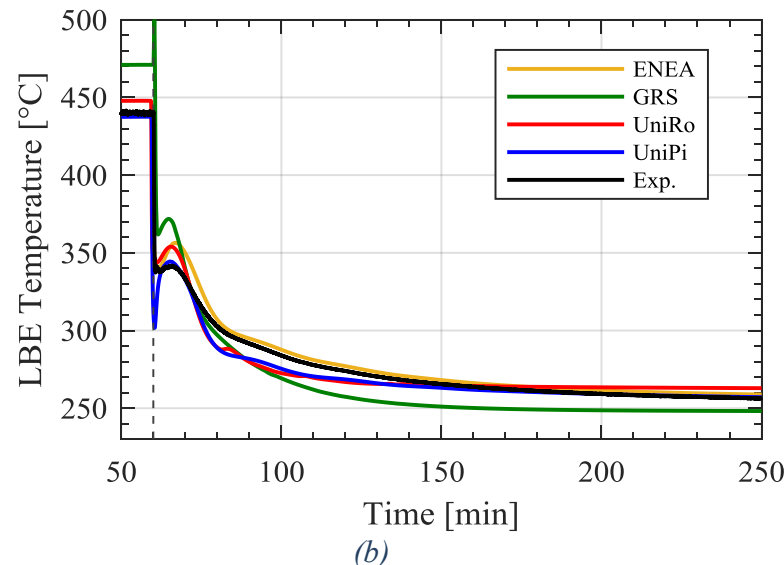

(b)

Figure 24. LBE temperature at the FPS inlet (a) and outlet (b); (Test-3)
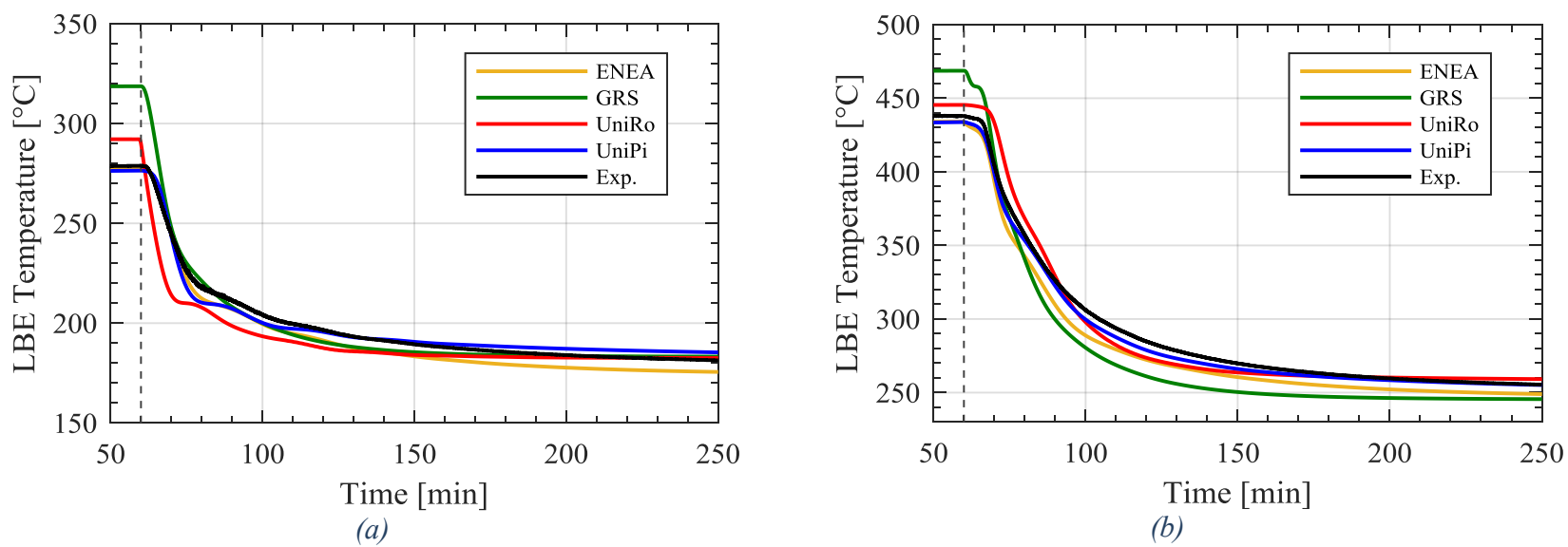

Figure 25. LBE temperature at the HX outlet (a) and inlet (b); (Test-3) 


\section{CONCLUSIONS}

The SESAME benchmark on thermal-hydraulic STH codes was illustrated and the main outcomes for post-test simulations were discussed. More specifically, the benchmark activity dealt with the comparative simulation of the NACIE-UP LBE cooled facility for three reference tests specially designed for the achievement of this task. The reference tests were: a gas lift reduction (Test-1), an FPS power level reduction (Test-2) and a PLOFA-like event (Test-3). On the basis of the benchmark requirements, the participants involved in this analysis used four different STH codes to model the experiments, namely: CATHARE for ENEA, ATHLET for GRS, RELAP5-3D for the University of Rome and RELAP5/Mod3.3 for the University of Pisa. After the release of the experimental data foreseen for the post-test simulation phase, the participants performed an upgrade of their numerical models with respect to the blind simulations initially carried out.

Concerning the post-test simulation of these three fundamental tests, a sufficiently good agreement was found among the participants and with experimental data in both steady state and transient conditions. The observed discrepancies in the LBE mass flow rate were mainly related to the specific parameter adopted to set the numerical model, as the pressure loss coefficients or the gas circulation model. The maximum discrepancy of the simulated mass flow rates was in the order of $\pm 10 \%$ for both enhanced circulation condition (Test-1, Test-2 and S.St.-1 in Test-3) and natural circulation condition (S.St.-2 in Test-3). Accordingly, similar discrepancies were found for the FPS and HX temperature difference. The loop average temperature exhibited major discrepancies that were presumably related to the assumption made for the HX thermal model that mostly affected the heat transfer towards this component, primarily the thermal conductivity of the stainless-steel powder filling the double tube gap. In fact, lower values of the overall heat transfer coefficients led to higher values of the average temperature in the primary loop. Differences were also observed in the loop pressure, presumably because of the different established loop temperatures (affecting the LBE density), the choice of the LBE level in the expansion vessel or the vertical elevation of the node where the pressure was measured. Minor differences were found in the water outlet temperature (HX secondary side) probably due to the choice of the water density value used to compute the water mass flow rate from the volumetric flow rate.

Despite these differences the transient behaviour was adequately reproduced, by the participant to the benchmark, for each of the simulated tests. In particular, the mass flow prompt decrease and the following damped oscillating trend were predicted by all the participants, as well as the temperature change, which showed similar trends in all the reference measurement positions (as the FPS outlet temperature prompt increase or decrease).

In conclusion, from the post-test analysis of the numerical results, it emerged that the adopted STH codes represent a promising numerical tool for predicting a variety of conditions related to both operational and accidental transients reproduced by a facility like NACIE-UP.

\section{ACKOWLEGMENT}

This work was performed in the framework of the H2020 SESAME project. This project has received funding from the Euratom research and training program 2014-2018 under grant agreement No 654935.

\section{NOMENCLATURE}

$\begin{array}{ll}\text { ATHLET } & \text { Analysis of THermal- hydraulics of LEaks and Transients } \\ \text { CATHARE } & \text { Code for Analysis of Thermalhydraulics during an Accident of Reactor and safety Evaluation } \\ \text { CEA } & \text { Commissariat à l'Énergie Atomique } \\ \text { CFD } & \text { Computational Fluid Dynamics } \\ \text { ENEA } & \text { Agenzia nazionale per le nuove tecnologie, l'energia e lo sviluppo economico sostenibile } \\ \text { FORTRAN } & \text { FORmula TRANslation } \\ \text { FPS } & \text { Fuel Pin Simulator } \\ \text { GRS } & \text { Gesellschaft Fur Anlagen Und Reaktorsicherheit } \\ \text { HLM } & \text { Heavy Liquid Metal } \\ \text { HX } & \text { Heat eXchanger } \\ \text { LBE } & \text { Lead-Bismuth Eutectic } \\ \text { LOFA } & \text { Loss Of Flow Accident } \\ \text { NACIE-UP } & \text { NAtural CIrculation Experiment- UPgraded } \\ \text { NPP } & \text { Nuclear Power Plant } \\ \text { PLOFA } & \text { Protected Loss Of Flow Accident } \\ \text { RBMK } & \text { Reactor Bolshoi Moschnosti Kanalynyi } \\ \text { RELAP } & \text { Reactor Loss Of Coolant Analysis Program } \\ \text { S.St. } & \text { Steady State } \\ \text { STH } & \text { System Thermal-Hydraulic } \\ \text { TDPJUN } & \text { Time dependent junction } \\ \text { TDPVOL } & \text { Time dependent volume }\end{array}$


Nuclear Engineering and Design 353 (2019) 110279, https://doi.org/10.1016/j.nucengdes.2019.110279

TFM

TMDPJUN

TMDPVOL

UniPi

UniRo
Thermal flow meter

Time dependent junction

Time dependent volume

University of Pisa

"Sapienza" University of Rome

\section{REFERENCES}

M. Angelucci, D. Martelli, G. Barone, I. Di Piazza, N. Forgione, "STH-CFD codes coupled calculations applied to HLM loop and pool systems", Science and Technology of Nuclear Installations, Vol. 2017, Article ID 1936894, 2017.

ATHLET User’s Manual, 2016, “ATHLET/Mod.3.1 Cycle A, GRS(mbH)”, 2016.

G. Barone, N. Forgione, D. Martelli, W. Ambrosini, 2013, "System codes and a CFD codes applied to loop- and pooltype experimental facilities”. CERSE-UNIPI RL 1530/2013/Adp MSE-ENEA LP2.C1.

S.K. Chen, N.E. Todreas , N.T. Nguyen, "Evaluation of existing correlations for the prediction of pressure drop in wire-wrapped hexagonal array pin bundles", Nuclear Engineering and Design, Vol. 267, pp. 109-131, 2014.

S.K. Cheng, N.E. Todreas, "Hydrodynamic models and correlations for bare and wire-wrapped hexagonal rod bundles - bundle friction factors, sub-channel friction factor and mixing parameters”, Nuclear Engineering and Design, Vol. 92, pp. 227-251, 1986.

C.B. Davis, A.S. Shieh, 2000, “Overview of the Use of ATHENA for Thermal-Hydraulic Analysis of Systems with Lead-Bismuth Coolant”, 8th International Conference on Nuclear Engineering, INEEL/CON-2000-00127.

I. Di Piazza, M. Angelucci, R. Marinari, M. Tarantino. N. Forgione, "Heat transfer on HLM cooled wire-spaced fuel pin bundle simulator in the NACIE-UP facility", Nuclear Engineering and Design, Vol. 300, Pages 256-267, 2016.

I. Di Piazza, M. Angelucci, G. Polazzi, V. Sermenghi, "NACIE-UP data for PLOFA experiment", Deliverable 4.10, SESAME EU Project, 2017.

N. Forgione, M. Angelucci, G. Barone, M. Polidori, A. Cervone, I. Di Piazza, F. Giannetti, P. Lorusso, T. Hollands, A. Papukchiev, "Blind Simulations of NACIE-UP Experimental Tests by STH Codes", ICONE26, London, England, July 22-26, 2018.

G. Geffraye, O. Antoni, M. Farvacque, G. Kadri, Lavialle, B. Rameau, A. Ruby, "CATHARE 2 V2.5_2: a Single Version for Various Applications”, Proceeding of NURETH-13, Japan, 2009.

I.E. Idelchik, 2003, Handbook of hydraulic Resistance, 3rd edition, Jaico Publishing House.

R. Marinari, "Pre-test CFD analysis of the rod bundle experiment in the Heavy Liquid Metal facility NACIE-UP”, Master of Science Thesis, University of Pisa, 2014.

D. Martelli, N. Forgione, G. Barone, and I. di Piazza, "Coupled simulations of the NACIE facility using RELAP5 and ANSYS FLUENT codes”, Annals of Nuclear Energy, Vol. 101, pp. 408-418, 2017.

V. Narcisi, P. Lorusso, F. Giannetti, A. Alfonsi, G. Caruso, 2019, "Uncertainty Quantification method for RELAP5-3D C using RAVEN and application on NACIE experiments”, Annals of Nuclear Energy, Vol. 127, pp. 419-432, 2019.

OECD/NEA Nuclear Science Committee, 2015 edition, Handbook on Lead-bismuth Eutectic Alloy and Lead Properties, Materials Compatibility, Thermal-hydraulics and Technologies.

M. Polidori, "Implementation of Thermo-Physical Properties and Thermal-Hydraulic Characteristics of Lead-Bismuth Eutectic and Lead on CATHARE Code”, Rapporto Tecnico ENEA, NNFISS - LP1 - 001, 2010.

K. Rehme, "Pressure drop correlations for fuel element spacers”, Nuclear Technology, Vol. 17, pp. 15-23, 1973.

RELAP5 Code Manual, "RELAP5/Mod3.3 code manual Volume I: Code structure, System models, and Solution methods". Nuclear Safety Analysis Division; Information Systems Laboratories, Inc. Rockville, Maryland Idaho Falls, 2001.

RELAP5-3D® Code Manual, The RELAP5-3D Code Development Team, INEEL-EXT-98-00834, 2013. 
D. Rozzia, G. Fasano, I. Di Piazza, M. Tarantino, "Experimental investigation on powder conductivity for the application to double wall heat exchanger (NACIE-UP)", Nuclear Engineering and Design, Vol. 283, pp. 100-113, 2015.

SESAME Handbook, Vv.Aa., "Thermal Hydraulics Aspects of Liquid Metal Cooled Nuclear Reactors", Edited by Ferry Roelofs, Elsevier Ltd., ISBN: 978-0-08-101980-1, 2019. 